\title{
O mercado da soja no Paraguai: expansão, consolidação e momento atual
}

\author{
Raimundo Christian Oliveira Soares ${ }^{1}$
}

\begin{abstract}
Resumo
No mercado mundial agrícola, a soja tem sido o produto mais comercializado e vendido, impactando fortemente na economia de países desenvolvidos e, principalmente, nos em desenvolvimento, como é o caso do Paraguai. O objetivo desta investigação é analisar as características e configurações do mercado da soja no Paraguai, além de identificar os atores envolvidos nos principais processos desse mercado e a importância destes para a consolidação da cadeia da soja no país. Para isso, foi feita uma revisão bibliográfica de obras que abordam a temática da soja numa visão histórica e que influenciaram o momento atual dessa cultura no país, período em que o mercado da soja já se encontra consolidado, o que podemos constatar com dados estatísticos relacionados à exportação e à produção desse produto. Constatou-se com a pesquisa que a soja pode ser considerada "La coluna vertebral del agronegocio en Paraguay", devido a sua importância para a economia do país.
\end{abstract}

Palavras chaves: Agronegócio. Soja. Grandes empresas agrícolas.

\begin{abstract}
In the world agricultural market, soy has been the most marketed and sold product, impacting heavily on the economies of developed and especially developing countries, such as Paraguay. The objective of this research is to analyze the characteristics and configurations of the soybean market in Paraguay, besides identifying the actors involved in the main processes of this market and the importance of these for the consolidation of the soybean chain in the Country. materials that work about soy in historical view and that influenced the current moment of the culture in the Country, period in which already has a consolidation of the market of the soybean and that we can verify with statistical data related to export and production. It was verified with the research that the soybean can be considered "the vertebral column of the agribusiness in Paraguay", due to its importance for economy of the Country.
\end{abstract}

Keywords: Agribusiness. Soy. Large agricultural enterprises.

\section{Introdução}

A soja, hoje, é um dos produtos agrícolas mais produzidos e comercializados no mundo, com sua produção global chegando em 317.253 milhões de toneladas, em uma área de 118.135 milhões de hectares, no ano 2014/2015 (EMBRAPA, 2016). Dentre os principais produtores de soja no mundo, podemos ver, em primeiro lugar, os Estados Unidos, com uma produção de 104.78 milhões de toneladas no ano de 2015/2016; em seguida, temos o Brasil, com 97.00 milhões de toneladas; e, na sequência, vêm a Argentina, com 57.00 milhões de toneladas; a Índia, com 11.50 milhões de toneladas; a China, com produção de 11.50 milhões

\footnotetext{
${ }^{1}$ Mestrando no Programa de Pós-Graduação em Políticas Públicas e Desenvolvimento, da Universidade Federal da Integração Latino Americana (UNILA). Bolsista Capes/Fundação Araucária.

raimundo.soares.unila@gmail.com
} 
de toneladas; e o Paraguai, com uma produção de 8.80 milhões de toneladas (CAPECO, 2016).

Os três maiores exportadores de soja no mundo, no ano de $2015 / 2016$, segundo Capeco (2016), são Brasil, com exportação de 49.75 milhões de toneladas; Estados Unidos, com exportação de 48.31 milhões de toneladas, e Argentina, com exportação de 8.50 milhões de toneladas. Dentre os principais exportadores de soja do mundo, o Paraguai está em quarta colocação, tendo exportado cerca de 4.447.514 toneladas de soja no ano de 2015, ocupando a quinta posição entre os maiores produtores de soja do mundo (CAPECO, 2016).

A principal região de produção de soja é a região oriental do país, que faz fronteira com Brasil e Argentina. Para alcançar esses números, foi necessária uma série de fatores, desde a chegada da soja até sua produção atual, dentre os quais está a entrada de estrangeiros e empresas transnacionais no país, que contaram com grandes incentivos do governo para seu fortalecimento e expansão. A soja possui praticamente três destinos: um deles é a industrialização (para fazer óleos ou ração animal); o outro é o uso de sementes, e o principal deles é a exportação in natura (CAPECO, 2016). As principais áreas de produção de soja são as áreas onde os estrangeiros chegaram, por meio da política de incentivo do governo da época. Os departamentos de Alto Paraná, Itapúa, Canindeyú, Caazapata e outros foram alcançados pela expansão da soja no país (INBIO, 2016).

Neste artigo, podemos classificar em três categorias os principais atores envolvidos no mercado da soja: as empresas de maquinarias agrícolas, as empresas de insumos agrícolas (que também exportam) e os produtores do país. É importante ver como esses atores estão presentes nos principais dados estatísticos do Paraguai, estando entre as principais exportadoras (Cargill e ADM, por exemplo, ocupando as primeiras posições) e entre os principais importadores de produtos agrícolas (como Syngenta e Agrosan) (Aduana, 2016). Já outras empresas como John Deere e New Holland estão entre as principais importadoras de máquinas agrícolas (CADAM, 2016).

O objetivo do estudo que resultou neste artigo foi aprofundar esse debate, analisando as características e configurações do mercado da soja no Paraguai, com destaque à expansão, à consolidação e ao momento atual. Além disso, é importante identificar os principais atores envolvidos nessa cadeia produtiva. 
Para a construção deste trabalho, foi feita uma revisão bibliográfica em textos que abordassem o tema da soja no Paraguai. Além disso, foram utilizados dados estatísticos sobre produção, exportação, importação, empresas, departamentos produtores e destino da soja. Para tanto, utilizaram-se dados do Ministério de la Agricultura y Ganaderia (MAG) e da Camara Paraguaya de Exportadores y Comercializadores de Cereales y Oleaginosas (CAPECO). Também foram usadas fontes como o Banco Mundial e Faostat para dados globais. Para o conhecimento da produção local, utilizaram-se as estatísticas da Inbio (Instituto de Biotecnologia Agrícola).

No setor de maquinários, fertilizantes, agroquímicos, sementes e comercialização, além de dados disponibilizados pelas empresas, foi consultada a Direccíon Nacional de Aduanas (Aduana Paraguai), que possui informações sobre as empresas exportadoras e importadoras do país.

\section{Produção e destino da soja no Paraguai}

Nesta seção será apresentado o resultado de uma análise dos elementos correspondentes ao funcionamento do mercado da soja no Paraguai e o andamento de sua produção. Para tanto, serão trabalhados três pontos principais: expansão e consolidação da soja no Paraguai, regiões de cultivo e destino de produção da soja no Paraguai.

\subsection{Expansão e consolidação da produção}

A partir de dados históricos a respeito da produção de soja, serão analisados comportamentos e variações em relação às informações sobre a quantidade de terras cultiváveis, produção e área com soja, de 1961 até 2014, na nação paraguaia. Como pode ser visto na figura 1, a área com soja no Paraguai começou a crescer de 1965 a 1969; não alcançando, porém, valores elevados. No ano de 1965, a área era de 11.250 hectares, e, no ano de 1966 , chegou a 14.280 , sendo que nos dois anos seguintes diminuiu, chegando a 8.400 hectares em 1968. No mesmo ano, as terras aráveis também tiveram uma queda, ficando com 
805.000 hectares (FAOSTAT, 2013; INBIO, 2015). Nesse momento, a soja ocupava cerca de $1 \%$ das terras aráveis no Paraguai.

Chegando aos anos 1970, com a entrada da agricultura mecanizada no Paraguai, provinda de brasileiros sulistas, a quantidade de terras com soja volta a crescer no país com mais força, o que se torna possível graças à ocupação de antigas propriedades e áreas florestais, as quais foram devastadas para o cultivo da soja. Segundo Rojas Villagra (2010), há, no sul do Brasil, uma crescente expansão da agricultura mecanizada, que se refletiu no Paraguai por meio de brasileiros que para lá migraram.

\section{Figura 1 - Área com soja e terras aráveis (em hectares) no Paraguai (1991-2012)}

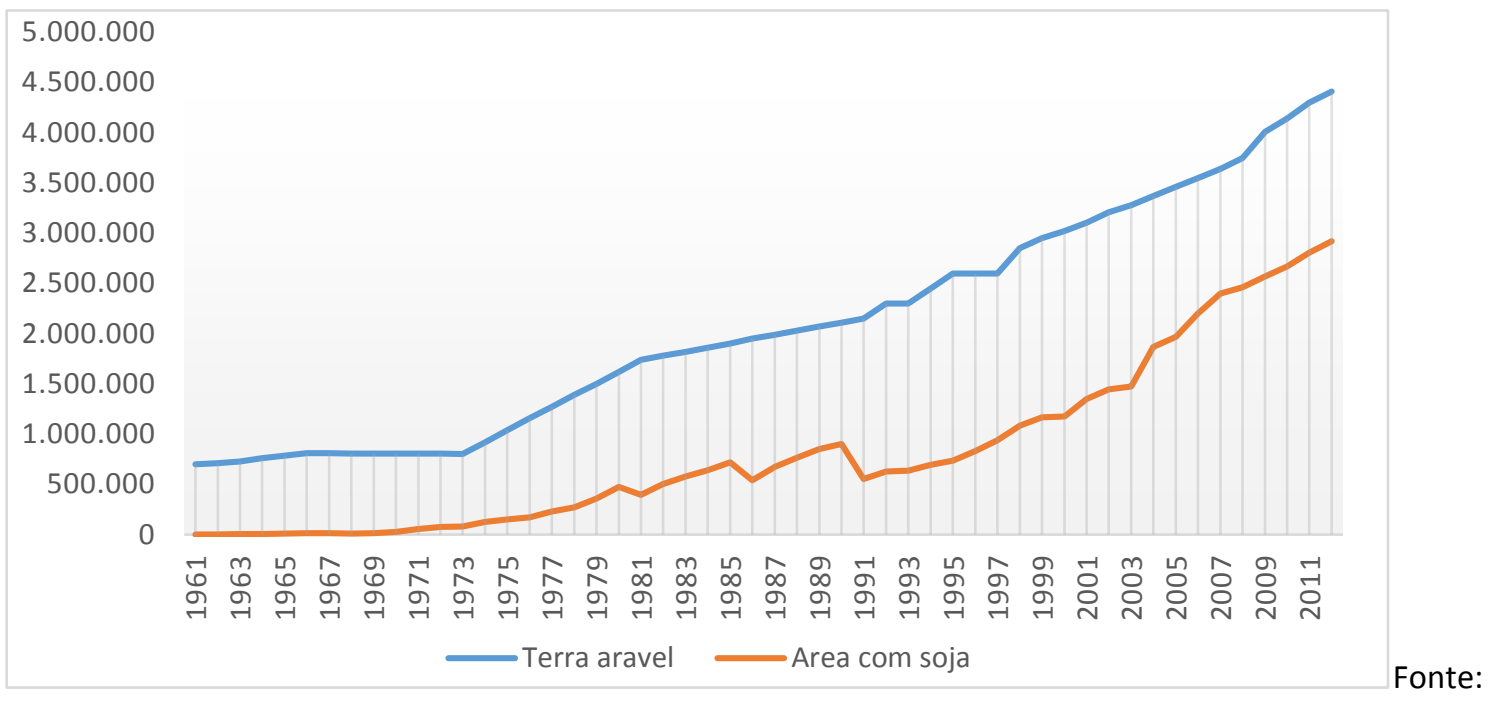

Fonte: FAOSTAT (2015).

Em 1969, a quantidade de terras aráveis era de 805.000 hectares; em 1970, essa quantidade manteve-se a mesma, e, nos anos seguintes, foi crescendo, como podemos ver na figura 1. Nos anos de 1971 a 1979, houve um crescimento constante da área com soja, o que se deve pela política de incentivo do governo paraguaio aos produtores de soja mecanizados, por meio do Programa Nacional de Soja, criado em 1972, no governo Stroessner (KLAUCK, 2011). O crédito proporcionado pelo Banco Nacional de Fomento permitiu uma intensificação de maquinário e tecnologia avançada, que também contribuiu para o aumento da área com soja, além das isenções das taxas de exportação (VERNETTI, 1974). Porém, esse crescimento, segundo Rojas Villagra (2010), teve seu desenvolvimento até meados dos anos 1980, período 
em que emerge uma crescente crise econômica e social, com grandes conflitos entre autoridades, movimentos campesinos e latifundiários.

Em meados dos anos 1990, houve um crescente aumento da quantidade de terras com soja no Paraguai. Segundo Rojas Villagra (2010), isso se deve à política neoliberal que o presidente Wasmoy adotou no país. Pode ser visto na figura 1, que, em 1995, o crescimento da área com soja começa a se destacar novamente, com superfície de 735.503 hectares, compreendendo $28,3 \%$ das terras totais aráveis do Paraguai, chegando, no ano de 1996, a $32,0 \%$ da área total de terras cultiváveis, com uma área de cultivo de soja de 833.005 hectares.

Um dos fatores importantes que mudou as características do crescimento da soja, segundo Rojas Villagra (2010), foi a entrada ilegal de sementes transgênicas no meio agrícola, no ano de 1999, além dos altos preços da soja no mercado internacional. Como podemos ver na figura 1, a partir desse período, a área com soja chega, em 2000, a corresponder a 39\% das terras totais cultiváveis do Paraguai e, no ano de 2004 , chega a $55,5 \%$, passando da metade das terras paraguaias cultiváveis.

Esse mercado seguiu aumentando nos anos seguintes, mais ainda com a incorporação de empresas que atuam com o mercado de sementes, insumos, máquinas e serviços. Nota-se também que a implantação de sementes transgênicas ajudou na produção da soja, que cresce demasiadamente. Além dessas sementes, também foram essenciais a fortificação dos insumos agrícolas vendidos por grandes empresas e a alta nos preços internacionais. Pode ser visualizado na figura 2 que, no ano de 1999, em uma área cultivada de 1.176 .460 hectares, obteve-se uma produção de 2.980 .058 toneladas, correspondentes a $2.533 \mathrm{~kg}$ por hectare, e, no ano de 2000, já se tem uma produção de 3.511.049 toneladas em uma área de 1.350 .000 hectare. No ano de 2010, a produção chegou a 8.628.553 toneladas em uma área de 2.870 .539 hectares (CAPECO, 2015).

Figura 2 - Área cultivada (hectares) e produção (toneladas) de soja no Paraguai (19992014) 


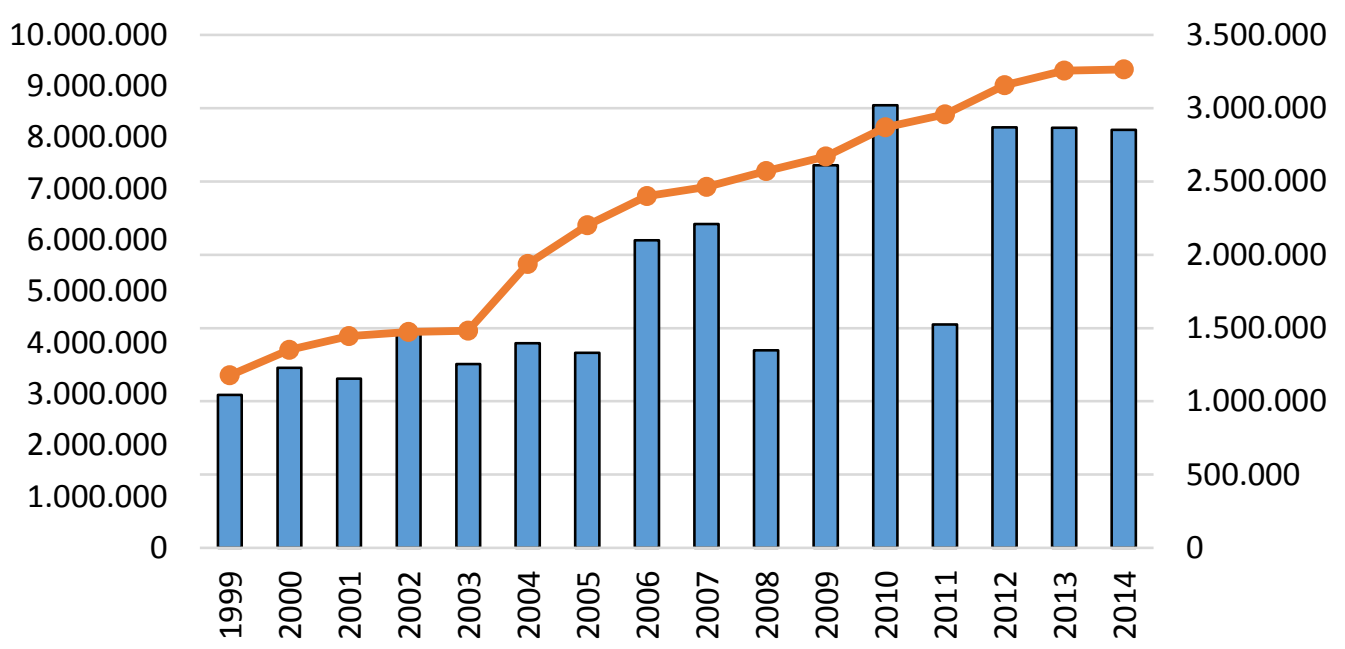

$\longrightarrow$ Produção $\longrightarrow$ Área cultivada

Fonte: Capeco 2015; Ministério de Agricultura y Ganaderia (2012).

Nos últimos anos, de 2010 a 2014, podemos ver que o mercado da soja está bastante consolidado no Paraguai, com dados que mostram áreas ocupadas por essa cultura, chegando a 2.920.000 hectares de soja plantada em 2012, e, em 2014, com 3.500.000 hectares de área cultivada, com produção de 9.975.000 toneladas (FAOSTAT, 2015).

\subsection{Destino de produção}

Nesta seção será analisada a dinâmica de exportação da soja no Paraguai de 1989 a 2014, o uso industrial e o consumo interno da soja, em farinha e azeite. Na figura 3, podemos observar que, desde o início dos anos 1990 até agora, os principais destinos da soja no Paraguai seguem sendo a exportação e a indústria, necessariamente nessa ordem de importância. Além disso, como principal categoria, a soja é exportada in natura, sendo que, em 1997, $77,6 \%$ das exportações foram in natura, enquanto $17,2 \%$ em exportação beneficiada. Em 2015, segundo dados da CAPECO, os maiores importadores de soja em grãos do Paraguai eram, em primeiro lugar, a União Europeia (com 37\%) e, em segundo lugar, a Rússia (com 25\%). Na sequência, Turquia e Brasil, cada um com 7\% do consumo de soja.

Outro ponto interessante é o consumo interno do grão no país. Na figura 3, podemos ver que, no ano de 2000, o consumo interno de soja no Paraguai era de 5,7\%; cinco anos 
depois, esse consumo passa a ser 3,2\%, enquanto a exportação chega a 69,6\%, em 2000, e alcança 71,3\% em 2005. Nos anos seguintes, nota-se o contínuo investimento na exportação da soja in natura, mesmo que em 2009 tenha ocorrido uma diminuição devido à crise (diminui para 62,6\%). Do ano de 2010 até 2012, ocorre uma recuperação do mercado de exportação, após a crise de 2008/2009. Uma das razões para investimento tão grande na exportação in natura seria a isenção de impostos para exportações de matérias-primas, o que não ocorre em produtos processados (ROJAS VILLAGRA, 2009).

\section{Figura 3 - Destino da soja no Paraguai (1997-2014)}

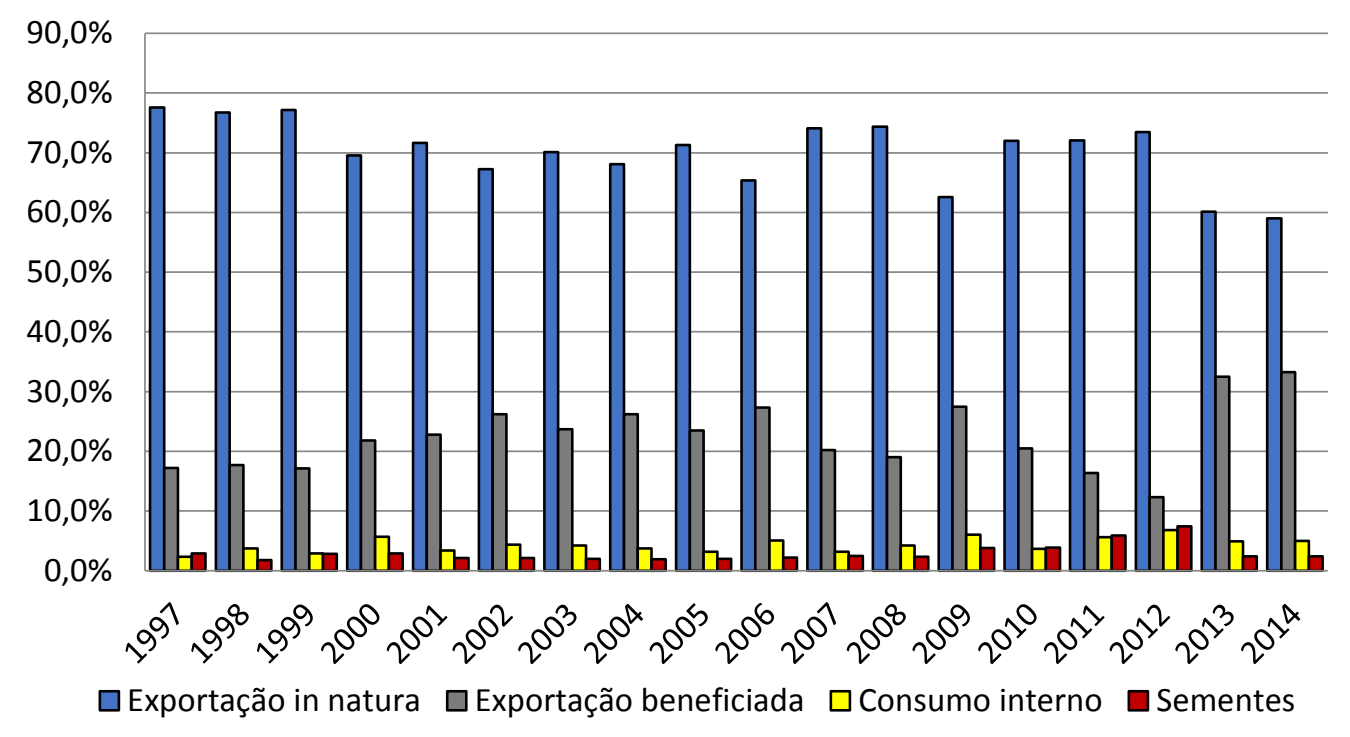

Fonte: Capeco (2015).

O consumo interno da soja pode ser classificado em duas categorias: óleo e farinha. Como podemos ver na figura 4, o consumo interno de maior volume é em farinha. Durante o final da década de 90 e início dos anos 2000, podemos ver que a soja processada em óleo cresceu e até se igualou à consumida em farinha, o que se deve pelo fortalecimento da indústria de óleo para uso alimentício (CAPECO, 2013). Além desse uso alimentício em margarinas, óleos de cozinha e maioneses, o óleo também passou a ter uso industrial em pinturas emulsificantes, lubrificantes, plásticos, solventes e resinas.

Figura 4 - Consumo interno de soja no Paraguai (1997-2015) 


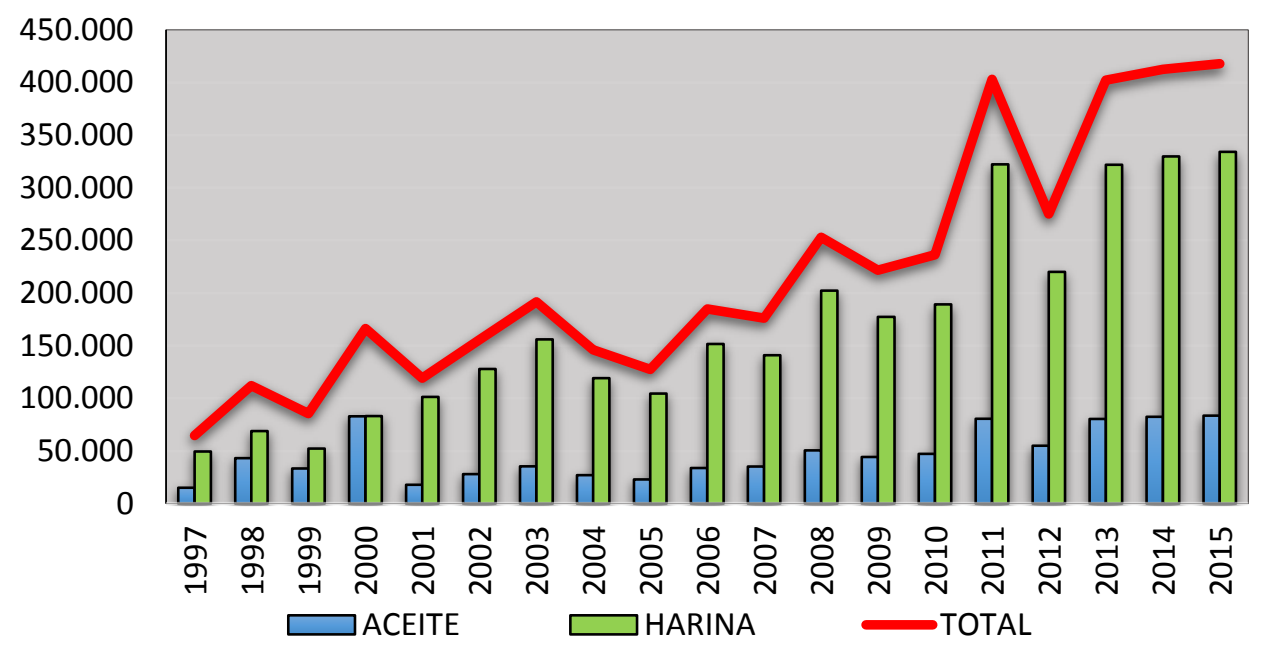

Fonte: Capeco (2015).

Dentre as principais utilidades da farinha de soja está a alimentação de frangos e suínos, o que vem crescendo do ano de 2010 a 2014, com previsão de aumento regular nos próximos anos (FAOSTAT, 2015).

\subsection{Regiões de produção de soja}

A partir dos temas trabalhados no início do artigo, podemos ver que a expansão da soja no Paraguai deu-se basicamente pela imigração dos brasileiros para a região de fronteira do Paraguai com o Brasil e pelos incentivos do governo paraguaio, com baixo preço das terras e programas de crédito do Banco Nacional de Fomento nos anos 1970 (ROJAS VILLAGRA, 2010; KLAUCK, 2011).

A região oriental do Paraguai foi o alvo da expansão agrícola da soja, o que até os dias atuais está muito presente e começa a se fortalecer em outros departamentos que não estão na região de fronteira. Na década de 1970, os principais departamentos com maior colheita de soja no Paraguai foram Itapúa, Misiones, Alto Paraná, San Pedro y Amanbay, que representaram cerca de $90 \%$ da área semeada em todo o Paraguai, sendo que somente o departamento de Itapúa semeou 56\% do total (II PROGRAMA NACIONAL DE SOJA, 1976). Porém, a partir dos anos 1990, pode-se notar que o departamento de Itapúa começa a deixar de ser o principal produtor de soja do país e passa ser o segundo de maior importância, ficando 
atrás do departamento de Alto Paraná, que se torna o maior produtor de soja do Paraguai (INBIO, 2015).

Figura 5 - Área semeada com soja por departamento no Paraguai (1990/91 - 2014/15)

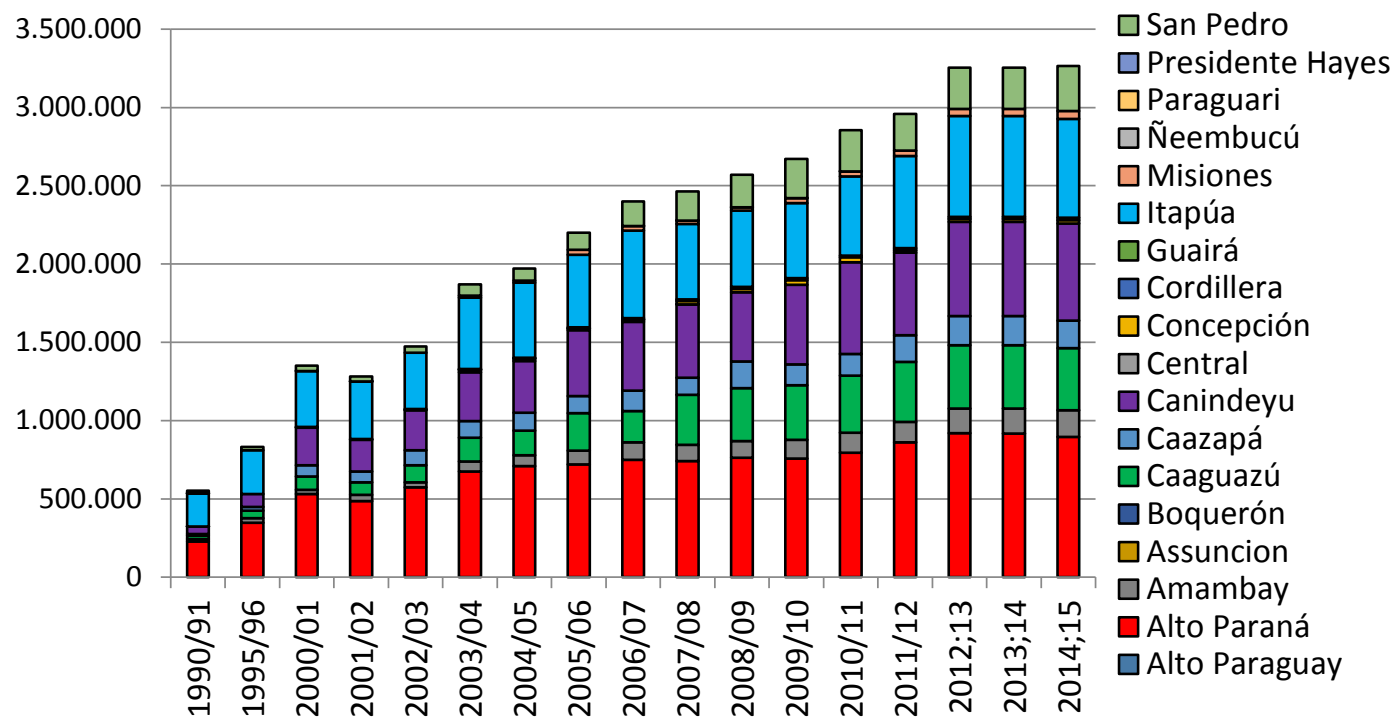

Fonte: INBIO (2015).

O departamento de Alto Paraná possui área total de $14.895 \mathrm{~km}^{2}$, onde de cada três pessoas, duas vivem na área urbana (ATLAS CENSAL DE PARAGUAY, 2004). Como podemos ver na figura 5, este departamento, de 1990/91 até o ano de 2014/15, segue sendo o principal semeador (e produtor) de soja no país, com algumas quedas que podem ser justificadas por crises nos mercados internacionais ou por estiagens, porém essas quedas ou baixas não significam que a expansão parou ou diminuiu. Como pode ser visto na figura 5 , segue um contínuo crescimento da área com soja, não somente no departamento de Alto Paraná, mas também em outros, como Caaguazú, que tinha área semeada de 49.030 hectares em 1990/91 e, em 2014/15, possuía 396.169 hectares.

O departamento de Itapúa, primeiro produtor de soja no Paraguai, possui área de $16.525 \mathrm{~km}^{2}$, onde residem cerca de 28 pessoas por $\mathrm{km}^{2}$, estando dividido em trinta distritos (ATLAS CENSAL DE PARAGUAY, 2004). Itapúa, nos anos 1990/91, começou com uma superfície de semeadura de 210.523 hectares; nos anos de 2014/15, chegou a 632.263 hectares. Mesmo 
com algumas quedas durante os anos, o departamento continuou sendo o segundo maior produtor de soja no país.

Outro departamento que tem crescido bastante de 1990/91 até 2014/15 é o departamento de Canindeyú, que ocupa área de $14.667 \mathrm{~km}^{2}$ e está divido em dez distritos, onde residem cerca de dez habitantes por $\mathrm{km}^{2}$, sendo que de cada quatro habitantes, três vivem em áreas rurais (ATLAS CENSAL DE PARAGUAY,2004). Canindeyú, em 1990/91, semeou uma área de 49.030 hectares, e, nos anos mais atuais, podemos ver um salto muito grande, elevando essa área a 619.524 hectares e o departamento a um nível bastante alto de significância para o mercado da soja.

Nos 1970, profissionais da área de plantio constataram que alguns departamentos como Caazapá, Guairá, Misiones, Paraguari e Cordillera (onde houve expansão da soja) não tinham tanto potencial para o plantio da cultura, previam um estancamento da produção devido aos maiores custos com insumos, pois essas áreas necessitavam de um maior cuidado em relação a aspectos ambientais. Além disso, havia a questão da competição com outros cultivos que possuíam prioridade (II PROGRAMA NACIONAL DE SOJA, 1976).

Como foi visto na figura 5, em uma visão mais atual, a expectativa não se confirmou. Em Caazapá, no ano de 1990/91, a área com soja foi de 8.931 hectares, e, nos dados mais atuais, podemos ver que o departamento continua com o cultivo, chegando a 176.562 hectares de área semeada em 20014/15. No departamento de Guairá, a área era muito pequena em 1990/91 (237 hectares), mas, atualmente, a quantidade de terras cultivadas no departamento chegou a 14.540 hectares em 2014/15 (ainda que o crescimento seja inquestionável, esse departamento não tem um peso expressivo no país). Em Misiones, a área semeada no ano de 1990/91 era de 159 hectares e, no ano de 2014/15, chega a 49.580 hectares. Os departamentos de Paraguari e Cordillera, em 1990/91, tinham respectivamente 414 e 3 hectares de área semeada, mais recentemente esse cultivo deixou de fazer parte das estatísticas.

Com a análise feita a partir da figura 5, verifica-se (mesmo que em alguns departamentos, como Paraguari e Cordillera, a soja não seja mais cultivada) que o grão tem se fortalecido, mesmo em departamentos nos quais não se viam condições favoráveis para a 
produção no início da expansão dos anos 1970. Além disso, é evidente o fortalecimento em outros departamentos, como podemos ver no Mapa 1.

\section{Mapa 1 - Área cultivada com soja na Safra 2014/2015}

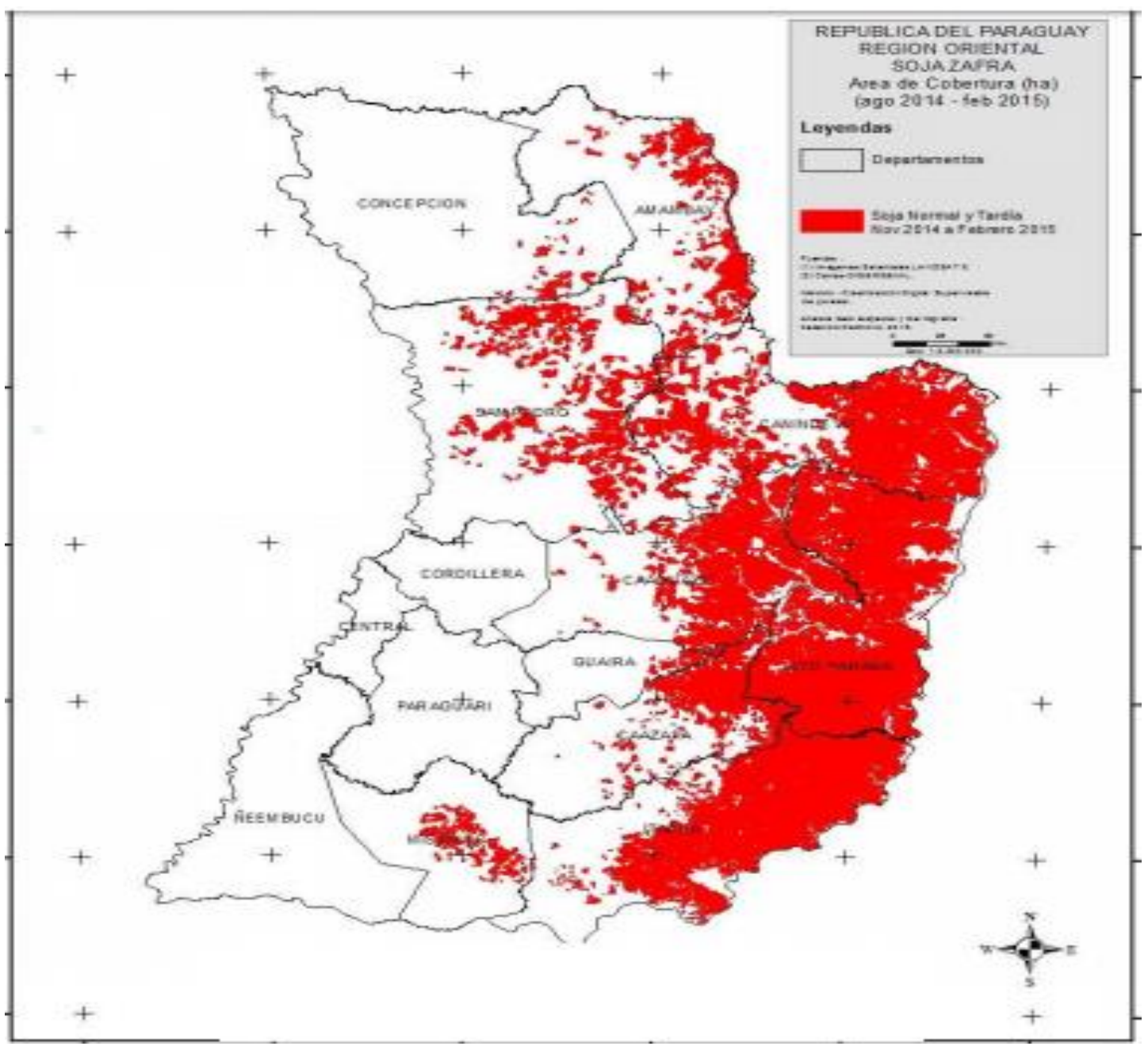

Fonte: Inbio ( 2016).

\section{Atores envolvidos no mercado da soja no Paraguai}

Este tópico do artigo tem como objetivo debater o papel dos atores envolvidos nas cadeias produtiva e comercial da soja, e como eles têm uma atuação fundamental no funcionamento desse mercado. Os atores fundamentais do funcionamento dos sistemas de produção e comercialização de soja, no Paraguai e no mundo, são as empresas de iniciativa privada, que, neste artigo, serão trabalhadas em corporações transnacionais e nacionais, 
sendo que as transnacionais possuem uma atuação muito impactante nas questões agropecuárias do país. Dentro dessa perspectiva, podemos ver as transnacionais como empresas que atuam além de seu país, buscando expandir suas atividades em várias nações por meio de subsidiárias ou alianças com diversas empresas (GUDYNAS Y BOUNOMO, 2007).

Este tópico do artigo tem como objetivo debater o papel dos atores que estão envolvidos na cadeia produtiva e comercial da soja, e como eles têm uma atuação fundamental no funcionamento do mercado da soja. Os atores fundamentais do funcionamento do sistema de produção e comercialização de soja, no Paraguai e no mundo, são as empresas de iniciativa privada, que, neste artigo, serão trabalhadas em corporações transnacionais e nacionais, sendo que as transnacionais possuem uma atuação muito impactante nas questões agropecuárias do país. Dentro dessa perspectiva, podemos ver as transnacionais como empresas que atuam além de seu país, buscando expandir suas atividades em várias nações por meio de subsidiárias ou alianças com diversas empresas (GUDYNAS; BOUNOMO, 2007).

As empresas transnacionais possuem grande influência nos processos de integração regional, nos organismos internacionais e nos governos de países que as recebem. Além disso, contam com uma crescente participação de capital transnacional no setor agrícola do país, núcleo do modelo do agronegócio implantado no território nacional, núcleo este que se define como principal organizador da estrutura de produção agrícola do país, que se orienta a partir das demandas do comércio internacional (ROJAS VILLAGRA, 2010).

Na próxima seção do artigo será revisado como as empresas transnacionais se caracterizam por sua oferta de produtos e serviços, e como elas atuam em relação à importação, industrialização e exportação.

\subsection{Empresas a montante}

Dentro do sistema de produção, processamento e venda da soja no Paraguai, as empresas transnacionais possuem uma atuação de extrema importância, pois todo esse processamento (referente às dimensões da produção convencional/agronegócio), depende dos produtos que são oferecidos por essas empresas que já se consolidaram no mercado 
mundial. Dentro da cadeia produtiva da soja, podemos ver a atuação das empresas nas áreas de maquinaria (tratores, colheitadeiras, pulverizadores, etc.), fertilizantes e agroquímicos.

\subsubsection{Maquinaria}

Com o grande volume de área e produção de soja, é necessário investir em maquinário de alta tecnologia e capacidade física para as várias atividades que demandam a sua produção. Nos anos de 2014 e 2015, segundo Cadam (2016), o Paraguai importou, respectivamente, cerca de 3.029 e 1.978 máquinas agrícolas, com importações feitas principalmente do Brasil, Índia, Estados Unidos, México e alguns países da Europa. Diante disso, existem algumas empresas que dominam, no Paraguai (e no mundo), dentro da linha de produção agrícola, o mercado maquinário. Entre essas empresas, podem ser destacadas como as cinco principais a John Deere, a Massey Ferguson, a Valtra, a New Holland e a Case (CADAM, 2016).

A empresa John Deere tem como principais distribuidores no Paraguai as companhias Automaq S.A.E.C.A e Kurosu \& Cia S.A. A Automaq foi fundada por Antonio Luis Pecci Saavedra, primeiramente com o nome de CIDE S.R.L, sendo fundada como Automaq somente no ano de 1961. Em 1985, Antonio Luis Pecci Saavedra viajou até os Estados Unidos, para assinar um contrato com a empresa John Deere, contrato vigente até os dias atuais ${ }^{1}$. A distribuidora Kurosu \& Cia S.A. iniciou suas atividades no ano de 1968, tendo seu primeiro contato com Schneider Logemann y cia. (SLC). Depois de 7 anos, foi absorvida pela John Deere, sendo até hoje concessionária no país². No ano de 2015, a empresa John Deere importou cerca de $32,2 \%$ dos tratores e $42,2 \%$ das colheitadeiras do Paraguay ${ }^{3}$.

As companhias Massey Ferguson e Valtra têm os seus produtos fabricados pela empresa AGCO, que produz os maquinários no Brasil e os exporta para o Paraguai e vários outros países da América Latina e alguns da África do Sul ${ }^{4}$. No ano de 2015, a Massey Ferguson importou cerca de $19,7 \%$ dos tratores e $6,8 \%$ das colheitadeiras, e a empresa Valtra, cerca de $16,4 \%$ de tratores ${ }^{5}$.

\footnotetext{
${ }^{1}$ http://www.automaq-jd.com.py/index.php?q=nota/166

2 http://www.kurosu.com.py/index.php?q=nota/166

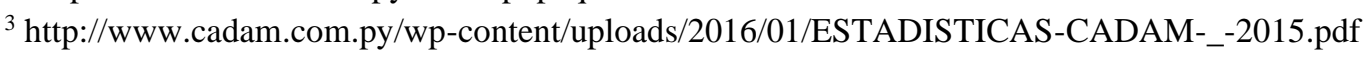

${ }^{4} \mathrm{http}$ ://www.agco.com.br/brands/massey-ferguson.html
} 
Figura 6 - Importação de tratores (2015) Figura 7: Importação colheitadeiras (2015)

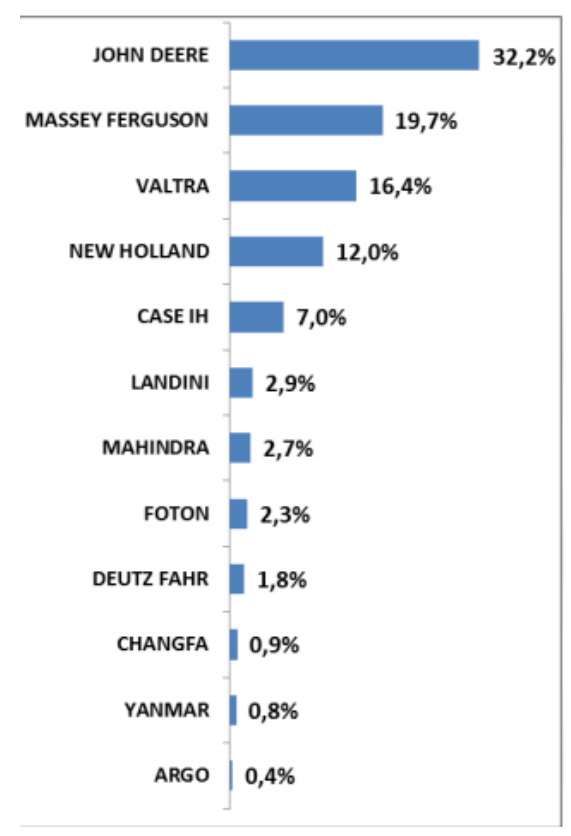

Fonte: CADAM, 2016.

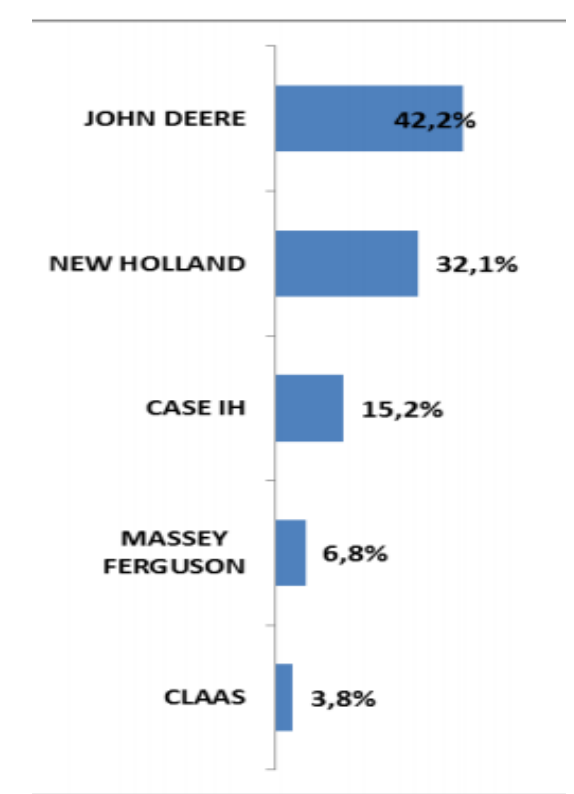

Fonte: CADAM, 2016.

A corporação CASE IH é fruto da união das empresas J.I Case e Cyrus McCormick, que aconteceu em 1985. No Paraguai, a marca Case é distribuída através da Ciabay, e, no ano de 2015 , importou cerca de $15,2 \%$ das colheitadeiras no país ${ }^{3}$. Outra empresa que tem sua marca vendida através da Ciabay é a New Holland, que, no ano de 2015, contou com cerca de 32,1\% das colheitadeiras e $12,0 \%$ dos tratores ${ }^{3}$, vendendo também sua marca através da Tape Ruvicha e da Agro Silo Santa Cantalia.

\subsubsection{Fertilizantes e agroquímicos}

Entre as empresas importadoras de produtos agrícolas no Paraguai, podemos ver, no ano de 2015, que a principal foi a empresa Agrotec S.A, que importou cerca de 82.342.398,57 dólares (ADUANA, 2016), e faz parte do Grupo Agrihold, fundando em 1990 junto à empresa Agrotec; estendendo, porém, suas atividades a outros países como Brasil, Uruguai e China ${ }^{5}$. A corporação foi fundada em 1990 por Túlio Luiz Neves Zanchet, passando a distribuir, já em

\footnotetext{
${ }^{5}$ http://www.agrihold.com/sobre-agrihold/ 
1992, no Paraguai, produtos da transnacional Cargill, e, de 1993 até os atuais dias, a ser distribuidora exclusiva da empresa BASF. No ano de 1994, a Agrotec S.A inicia a distribuição exclusiva dos produtos Fosmag 6 .

Outra grande importadora agrícola do Paraguai é a empresa Syngenta, que, no ano de 2015, importou cerca de 80.067.674,86 em dólares (ADUANA, 2016). A empresa tem sua sede na Suíça e distribuía seus produtos no Paraguai através de empresas que tinham a representação de seus produtos, como, por exemplo, a corporação Agrosan S.A (ROJAS VILLAGRA, 2009). No ano de 2012, a empresa Agrosan passa a ser denominada de Syngenta S.A (ADUANA, 2016).

A transnacional Monsanto, uma das maiores empresas de produtos agrícolas do mundo, vende seus produtos no Paraguai através de outras empresas. A principal representante dos produtos Monsanto no país é a corporação Agrofértil S.A, de fundadores brasileiros (ROJAS VILLAGRA, 2009). A empresa possui grande volume de importações no país, sendo que no ano de 2015 importou cerca 54.121.613,43 em dólares, estando entre as primeiras colocadas no ranking de importadoras do Paraguai (ADUANA, 2016). Segundo Rojas Villagra (2009), outra empresa que representa a Monsanto no Paraguai é a Dekalpar S.A, que, em 2015, importou cerca de 33.779.360,38 em dólares (ADUANA, 2016).

Quadro 1 - Empresas importadoras no Paraguai

\begin{tabular}{|l|r|r|}
\hline Empresa & $\mathbf{2 0 1 4}$ & $\mathbf{2 0 1 5}$ \\
\hline AGROTEC AS & $80.113 .735,80$ & $82.342 .398,57$ \\
\hline SYNGENTA PARAGUAY S.A. & $85.605 .924,30$ & $80.067 .674,86$ \\
\hline AGROFERTIL AS & $77.386 .153,60$ & $54.121 .613,43$ \\
\hline BAYER AS & $44.030 .256,20$ & $50.844 .161,57$ \\
\hline NOBLE PARAGUAY S.A. & $54.248 .108,20$ & $31.619 .309,77$ \\
\hline
\end{tabular}

Fonte: Aduana, 2016.

\footnotetext{
${ }^{6} \mathrm{http}: / /$ www.agrotec.com.py/quienes-somos/

COLÓQUIO - Revista do Desenvolvimento Regional - Faccat - Taquara/RS - v. 16, n. 3, jul./dez. 2019
} 


\subsection{Empresas a jusante}

A principal exportadora do Paraguai é a transnacional Cargill, surgida em 1865, ao final da guerra civil norte-americana, sendo responsável por cerca de $20 \%$ de todas as exportações do país (ADUANA, 2016). A empresa desponta como um armazém de grãos, fundado por WW Cargill, em Conover, Lowa, e, logo depois, houve a junção de seus dois irmãos, James e Sam, que estabeleceram a sede da empresa em La Crosse, Wisconsin ${ }^{7}$

Em 1978, a empresa Cargill Agropecuária S.A.C.I inicia suas atividades com a comercialização de algodão e soja. Em 1991, a transnacional constrói seu primeiro porto (Porto Paloma), localizado a $1 \mathrm{Km}$ do rio Paraná, momento em que a empresa começa a fortalecer suas importações e exportações. No ano de 2001, a empresa adere a uma nova estratégia, a de não trabalhar só com exportações, mas, além disso, inserir-se no mercado de fertilizantes, fortalecendo suas raízes no país.

Atualmente, a empresa abarca vários serviços no setor agrícola, como processamento de sementes oleaginosas e de cereais, sua comercialização como matéria-prima e para a indústria alimentícia, comercialização de insumos agrícolas e serviços vinculados a todas essas atividades, além de possuir sua própria companhia de navegação e dois portos, um próprio, sobre o rio Paraná, o Porto Paloma, e outro em consórcio, sobre o rio Paraguay, o Porto Unión, além de mais outros cinco portos minados no país e 37 silos espalhados por diversas regiões do Paraguai ${ }^{8}$.

Depois da Cargill, a empresa com maior volume de exportação no país é a ADM, que é responsável por cerca de $9,6 \%$ de todas as exportações, exportando a quantia de 678.375.306,07 em dólares em 2015 (ADUANA, 2016). A companhia, antes de ser nomeada ADM, foi fundada John W. Daniels, como Daniels Linseed Company, em 1902, em Minneapolis, Minnesota. No ano seguinte, George A. Acher junta-se a W. Daniels em Minnesota. No ano de 1905, o nome da empresa passa a ser Archer Daniels Linseed Company, e, depois da compra

\footnotetext{
${ }^{7}$ http://www.cargill.com./company/history/1865-1899/index.jsp

${ }^{8}$ http://www.cargill.com.py/default.asp?ch=2000573 
de várias outras companhias em 1923, a companhia muda seu nome para Archer Daniels Midland Company $(\mathrm{ADM})^{9}$.

A transnacional ADM começa a fazer parte do mercado da soja no Paraguai a partir dos anos 1997, por meio da compra das divisões locais de grão da Agrocereales e Silo Amambay. Atualmente, a empresa é responsável por cerca de 30\% do processamento da produção de grãos e sementes oleaginosas. Ao longo dos anos, a ADM construiu sua logística de transporte por meio da compra de uma empresa de camionagem, duas de transportes fluviais (Naviera Chaco e América Fluviais) e da execução de contrato para a construção de mais de sessenta barcaças. Atualmente a frota fluvial da ADM conta com cerca de treze rebocadores e 230 barcaças, que ajudam no transporte dos produtos agrícolas. A empresa conta também com um porto próprio e outros três locados ${ }^{10}$.

A empresa Bunge, responsável por cerca de 3\% das exportações totais no Paraguai, foi fundada em 1818, por Johann Peter Gottlieb Bunge, em Amsterdam, com o nome de Bunge \& CO. Com o passar dos anos, a empresa foi se estabelecendo no mercado mundial e se fixando em alguns países como Argentina e Brasil ${ }^{11}$. A transnacional instalou-se no Paraguai, no ano de 2006, como Bunge Paraguay, e atualmente é uma das mais influentes no mercado do agronegócio, com volume de grãos comercializados de 850.000 toneladas anuais.

A empresa é a terceira maior exportadora (entre as corporações agrícolas) no ranking de exportadores no país. Dos serviços oferecidos pela Bunge estão a distribuição de fertilizantes, a industrialização, a comercialização, recepção e armazenagem de grãos. A transnacional possui três portos, Porto CAIASA, Porto dos Fronteras e Porto Encarnacion (com capacidade para 25.000 toneladas de grãos), além de três armazéns que estão instalados nos departamentos de Canindeyu, no distrito de Curuguaty, com capacidade de 10.000 toneladas; no departamento de Alto Paraná, distrito de Naranjal, com capacidade de 34.000 toneladas; e o Cruci Guarany, localizado na estrada 10, km 356, Cruci Guarany ${ }^{12}$.

\footnotetext{
${ }^{9}$ http://www.adm.com/en-US/company/history/Pages/1920-1939.aspx

${ }^{10} \mathrm{http}: / /$ www.adm.com/en-US/worldwide/paraguay/Pages/default.aspx

${ }^{11} \mathrm{http}: / / \mathrm{www}$. bunge.com./company-history

${ }^{12} \mathrm{http}: / / \mathrm{www}$.bungeparaguay.com/?q=centros-de-almacenamiento
} 
A transnacional Louis Dreyfrus, foi criada por Leopodo Louis Dreyfrus, na região de Alsace, França, e tem como objetivo o cultivo e produção de materiais agrícolas em estado natural e industrializado, processamento e refino de produtos não processados e exportação de commodities. A Louis Dreyfrus Company começou suas atividades no Paraguai, a partir do ano de 2004, e possui como principais atividades a produção, processamento e transporte de produtos agrícolas, além da comercialização de fertilizantes e agroquímicos. A companhia possui oficinas comerciais em Canindeyu, Nueva Esperanza, na região norte do país, e em Alto Paraná, Santa Rita, na Região Sul.

\section{Quadro 2 - Empresas exportadoras no Paraguai}

\begin{tabular}{|l|r|r|}
\hline & \multicolumn{2}{|c|}{ Ano } \\
\hline Empresa & 2014 & 2015 \\
\hline CARGILL AGROPECUARIA SACI & $1.768 .738 .129,60$ & $1.415 .141 .890,06$ \\
\hline ADM PARAGUAY S.R.L. & $848.635 .528,20$ & $678.375 .306,07$ \\
\hline BUNGE PARAGUAY AS & $269.958 .480,30$ & $219.152 .765,30$ \\
\hline LDC PARAGUAY S.A. & $136.950 .799,20$ & $6.315 .024,92$ \\
\hline NOBLE PARAGUAY S.A. & $176.425 .618,10$ & $135.046 .978,35$ \\
\hline Fonte: Aduana (2016). & & \\
\hline
\end{tabular}

No ano de 2015, a empresa ampliou sua capacidade, criando mais dois armazéns, o de Curuguaty, Canindeyu, com capacidade de armazenamento de 13.000 toneladas de grãos, e outro em Tuna, Caazapá, com capacidade de 13.000 toneladas. A empresa conta também com a Caiasa (Complejo Agroindustrial Angostura S.A), que é uma associação com outras empresas. A LDC também conta com a Logica Paraguay, uma empresa de transporte fluviais, que é filiada da transnacional, com capacidade de transportar 1,3 milhões de toneladas por ano.

\section{Considerações finais}

Podemos observar que o mercado da soja, para chegar no atual nível, teve que passar por diversos processos e momentos históricos, além da forte participação de seus atores, que 
praticamente levaram esse modelo agrícola para o Paraguai. Dentre as principais causas de fortalecimento desse mercado no país, podemos perceber como principal a entrada dos estrangeiros (principalmente brasileiros) na região de fronteira do Paraguai, ação incentivada pelo governo da época, que passou a vender as terras com baixos preços, além de subsidiar os produtores que já tivessem tecnologia para cultivo. Isso, além dos altos preços no mercado mundial, fez com que houvesse um fortalecimento na produção e no mercado desde o princípio do cultivo da soja.

A soja do Paraguai tem como principal função a exportação, principalmente para a Europa. A exportação da soja é de grande peso para a economia do país, causando, sob certo ponto de vista, uma dependência dessa atividade, assim como ocorre em vários países da América Latina. Dentro do processo de exportação, existem atores que regem geralmente toda a cadeia produtiva da soja e de sua venda. Esses atores são as grandes empresas, geralmente transnacionais, que estão presentes em diversos países do mundo com seus produtos e tecnologias agrícolas. Essas grandes firmas estão no topo dos rankings de exportadores do Paraguai, além de também estarem entre os principais importadores com seus insumos agrícolas e maquinários.

Com os dados trabalhados, podemos observar a grande liberdade que essas empresas possuem no país para movimentar o mercado exportador e importador, formando um oligopólio de seus produtos e serviços, o que contribui para o desaparecimento de culturas típicas da região paraguaia. Também podemos ver na discussão feita neste artigo que é notável que as áreas com soja estão se expandido para outros departamentos além da fronteira oriental. Com o alto investimento em tecnologia agrícola, os produtores de soja podem expandir suas fronteiras agrícolas sobre áreas degradadas e desertificadas.

O processo de expansão de soja está muito fortalecido no país. Desde os anos 1970, esse processo vem sendo construído e fortalecido e conta com a participação de seus representantes na política do Paraguai, fortalecendo ainda mais o processo de expansão da soja e do próprio mercado. Diante disso, fica clara a tendência de aumento desse mercado, fortalecendo-se ainda mais, porém devemos analisar também a questão do comércio exterior, pois, se houver uma crise ou aumento nos preços, a economia do país pode ser prejudicada novamente, por ser praticamente dependente do monocultivo, especialmente o da soja. 


\section{Referências}

ADM. Adm company 2016. Disponível em: http://www.adm.com/enUS/company/history/Pages/1920-1939.aspx. Acesso em: 15 jun. 2016.

ADM. Adm Paraguay 2016. Disponível em: http://www.adm.com/enUS/worldwide/paraguay/Pages/default.aspx. Acesso em: 15 jun. 2016.

ADUANA. Dirección nacional de aduanas 2016. Disponível em: http://www.aduana.gov.py/. Acesso em: 15 jun. 2016.

AGCO. Distribuidora Massey Ferguson 2016. Disponível em:

http://www.agco.com.br/brands/massey-ferguson.htm. Acesso em: 15 jun. 2016.

AGRIHOLD. Distribuidora de insumos agrícolas 2016. Disponível em: http://www.agrihold.com/sobre-agrihold/. Acesso em: 18 jun. 2016.

AGROTEC. Agrotec Paraguay 2016. Disponível em: http://www.agrotec.com. py/quienessomos/. Acesso em: 18 jun. 2016.

AUTOMAQ S.A.E.C.A. Distribuidora John Deere 2016. Disponível em: http://www.automaqjd.com.py/index.php?q=nota/166 . Acesso: 18 jun. 2016.

BANCO MUNDIAL. Banco mundial Paraguay 2016. Disponível em:

http://datos.bancomundial.org/pais/paraguay. Acesso: 18 jun. 2016.

BUNGE. Bunge company 2016. Disponível em: http://www.bunge.com./company-history. Acesso em: 20 jun. 2016.

BUNGE. Bunge Paraguay 2016. Disponível em:

http://www.bungeparaguay.com/?q=centros-de-almacenamiento. Acesso em: 20 jun. 2016

CADAM. Camara de distribuidores de automotores y maquinaria 2016. Disponível em: http://www.cadam.com.py/.Acesso: 12 maio 2016.

CAPECO. Cámara Paraguaya de exportadores y comercializadores de cereales y oleaginosas 2016. Disponível em: http://capeco.org.py/. Acesso em: 18 dez. 2015.

CARGILL. Company Cargill 2016. Disponível em:

http://www.cargill.com./company/history/1865-1899/index.jsp. Acesso em: 21 jun. 2016

CARGILL PARAGUAY. Cargill Paraguay 2016. Disponível em:

http://www.cargill.com.py/default.asp?ch=2000573. Acesso em: 21 jun. 2016 
CASEIH. Distribuidora Caseih 2016. Disponível em:

http://www.caseih.com/latam/ptbr/sobre-a-case-ih/hist\%C3\%B3ria Acesso em: 21 jun. 2016.

EMBRAPA, Empresa Brasileira de Pesquisa e Agropecuária. Disponível em: https://www.embrapa.br/soja. Acesso em: 16 ago. 2016.

FAOSTAT. Organización de las naciones unidas para la alimentación y agricultura dirección de estadística 2016. Disponível em: http://faostat3.fao.org/browse/area/169/S. Acesso em: 21 jun. 2016.

GUDYNAS, Eduardo y Buonomo, Mariela. Integración y Comercio (Montevideo: Coscoroba Ediciones) 2007. Disponível em:

http://www.integracionsur.com/publicaciones/DiccIntComAC2p.pdf, Acesso em: 1 jun. 2016

INBIO. Instituto de biotecnologia agrícola 2016. Disponível em: http://www.inbio.org.py/. Acesso em: 22dez. 2015.

KLAUCK, R. C. A luta dos brasiguaios pelo acesso à terra no Paraguai (1970-1980). In: Congresso Internacional de História. Anais... 2001. Disponível em:

http://www.cih.uem.br/anais/2011/trabalhos/57.pdf. Acesso em: 1 jun. 2016.

KUROSU \& CIA. S.A. Distribuidora John Deere 2016. Disponível em:

http://www.kurosu.com.py/index.php?q=nota/166. Acesso em: 20 jun. 2016

LDC. Luis Dreyfrus Paraguay 2016. Disponível em:

http://www.Idcom.com/py/es/nosotros/louis-dreyfus-company-en-paraguay/. Acesso em: 20 jun. 2016

REPORTÉR BRASIL. Os impactos socioambientais da soja no Paraguai 2010. BASE investigaciones sociales. Disponível em: http://reporterbrasil.org.br/documentos/PARAGUAI_2010PT.pdf. Acesso em: 20 jun. 2016 ROJAS VILLAGRA. L. Actores del agronegocio en Paraguay. BASE Investigaciones Sociales y Diakonia - Acción Ecuménica Sueca. Asunción: 2009.

VERNETI, Francisco. Possibilidades da cultura da soja no Paraguay. J. A cultura da soja no Paraguay. Acesso em: 8 maio 2016. Disponível em: https://books.google.com.br/books?id= Po4gAQAAIAAJ\&pg=PP1\&dq=Francisco+Venetti,+1974 \&hl=pt-

$B R \& s a=X \& v e d=0 a h U K E w i A \_P u 08 v N A h U E W p A K H V n s A H E Q 6 A E I H j A A \# v=$ onepage\&q\&f=true. 